\title{
Water quality response to hydropeaking regulation of the Three Gorges Dam and Gezhouba Dam, China
}

\author{
Meili Feng ${ }^{1}$, Yue Zhu ${ }^{1}$, Jianfeng Ren ${ }^{1}$, and Shuyang $\mathrm{Xu}^{1}$ \\ ${ }^{1}$ University of Nottingham Ningbo China Faculty of Science and Engineering
}

January 12, 2022

\begin{abstract}
Hydropeaking as the most prominent feature of flow alterations resulting from hydropower plants has received attention worldwide. Ramifications of hydropower on the downstream river systems mainly focus on hydrological regimes or long-term water quality changes. Exceptional knowledge is expected on the sub-daily changes of water qualities in the downstream river reach that is affected by the hydropeaking. In this study, we investigate the dynamics of hydropeaking and thermopeaking at the outlet of the Three Gorges Dam TGD using a high temporal resolution dataset, and inspect its association with water chemistry indices. Hourly measurements are analysed for the downstream station Yunchi, and compared with the upstream station Nanjinguan. The results show that along with water temperature, water quality indices such as dissolved oxygen, total Phosphorus, total nitrogen, $\mathrm{PH}$, and electricity conductivity all show evident 'peaking' phenomenon in a short time. These divergent variations, however, are not valid for non-hydropeaking affected indicators including turbidity, permanganate index, and ammonia nitrogen. These hydropeaking-induced perturbations are mitigated by the flood control operation from July to September. This study demonstrates that water quality indices are sensitive to hydropeaking and thermopeaking with respect to the magnitude of change and the seasonal component during a year. The results provide additional evidence for the environmental impacts of hydropower regulation on the receiving river reach, and bridge the gap between hydropeaking studies and thermopeaking, and study water qualities variations that were seldom connected from the same temporal perspective in river research.
\end{abstract}

\section{Hosted file}

1.10.docx available at https://authorea.com/users/455012/articles/552467-water-qualityresponse-to-hydropeaking-regulation-of-the-three-gorges-dam-and-gezhouba-dam-china 

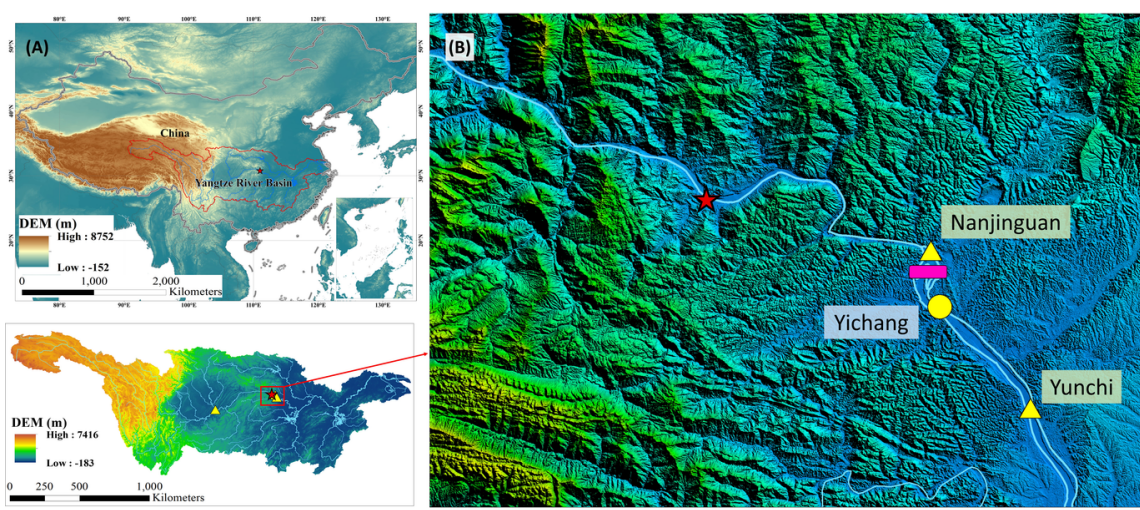

文 Three Gorges Dam

DEM (m)

$20 \quad 30$

紫

$\triangle$ Water quality monitoring station

Main river reaches

Low : -31

- Hydrologic gauging station

Gezhouba Dam

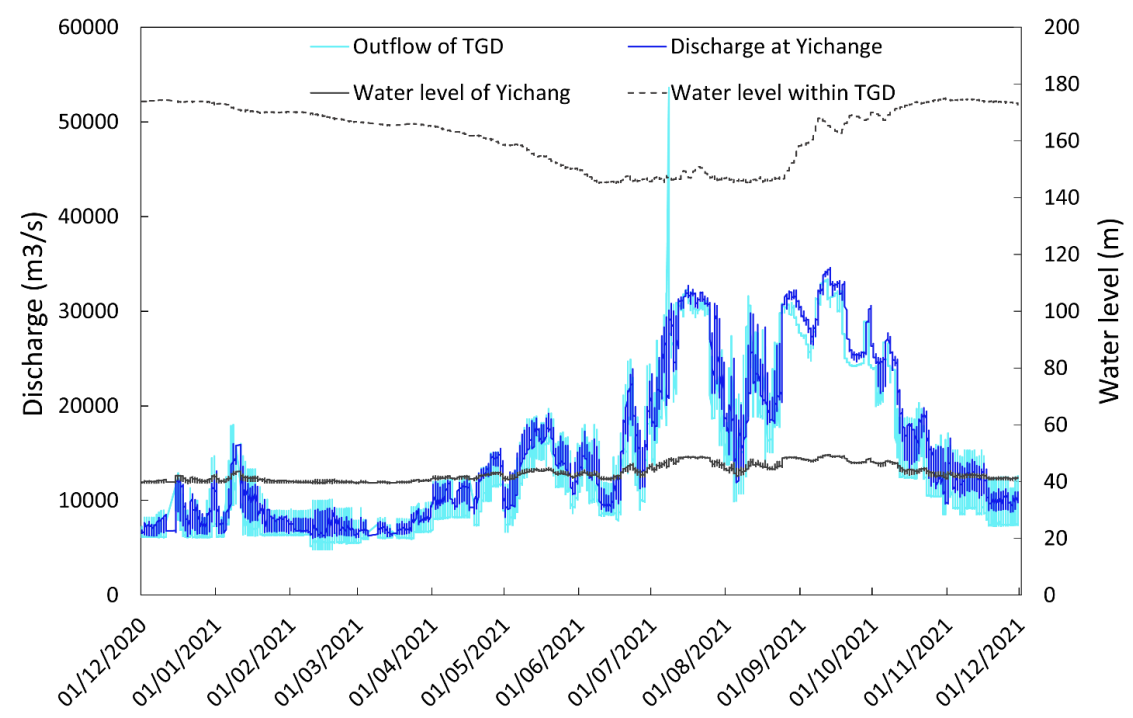



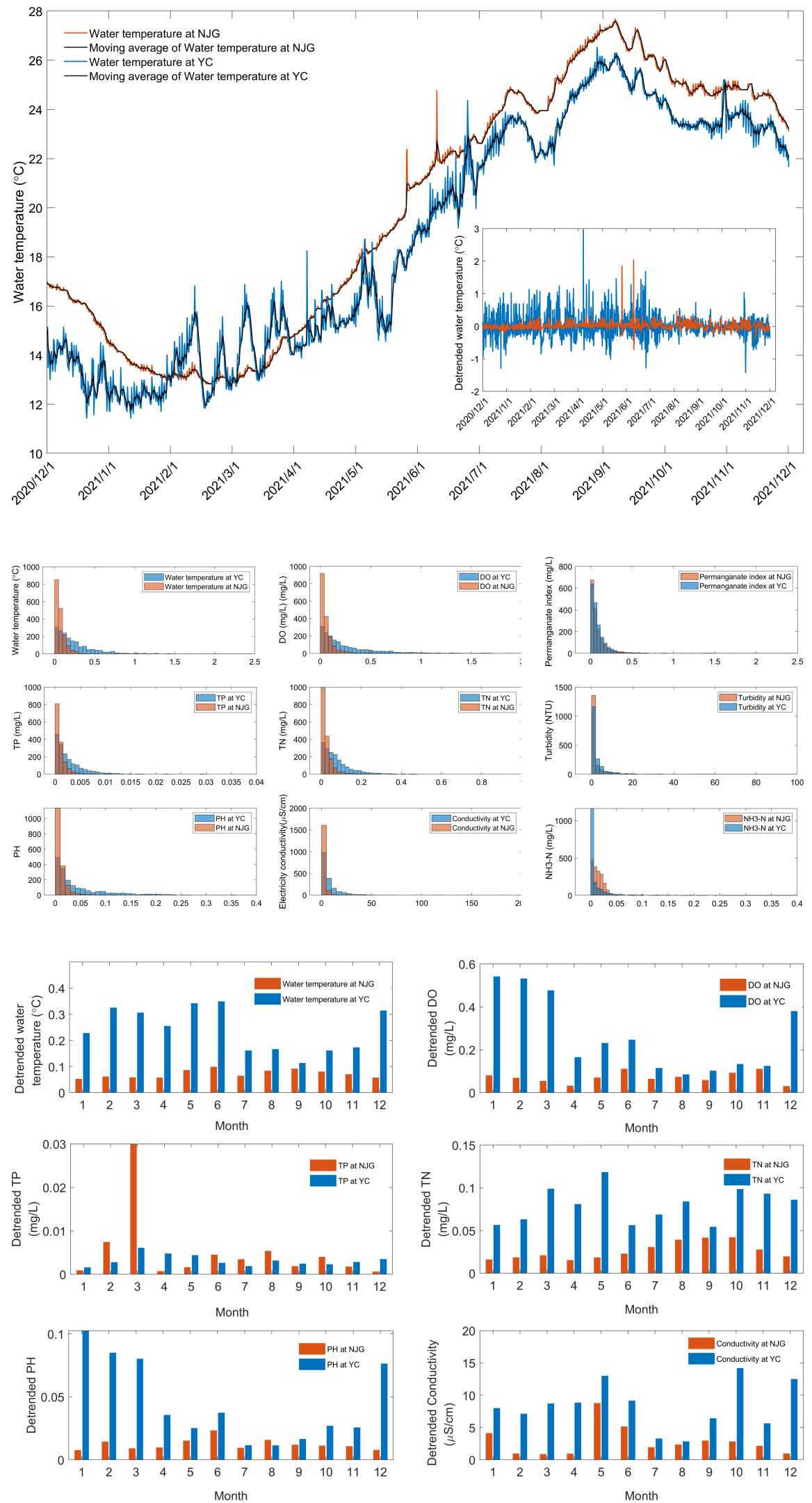


\section{Hosted file}

Figures.docx available at https://authorea.com/users/455012/articles/552467-water-qualityresponse-to-hydropeaking-regulation-of-the-three-gorges-dam-and-gezhouba-dam-china

Hosted file

Tables.docx available at https://authorea.com/users/455012/articles/552467-water-qualityresponse-to-hydropeaking-regulation-of-the-three-gorges-dam-and-gezhouba-dam-china 